\title{
Clinical Outcomes of Witnessed and Monitored Cases of In-Hospital Cardiac Arrest in the General Ward of a University Hospital in Korea
}

\author{
Gyu Rak Chon MD, Jinmi Lee RN, Yujung Shin RN, Jin Won Huh MD PhD, \\ Chae-Man Lim MD PhD, Younsuck Koh MD PhD, and Sang-Bum Hong MD PhD
}

\begin{abstract}
BACKGROUND: There are few studies of the epidemiology and clinical outcomes of patients with in-hospital cardiac arrest (IHCA) in a general hospital ward. OBJECTIVE: To investigate the clinical outcomes of IHCA cases that occurred in the general ward of a university hospital and that were witnessed and/or monitored. METHODS: We prospectively gathered data on all IHCAs in the general ward of Asan Medical Center, Seoul, South Korea, that were recorded by the Medical Emergency Team between March 2008 and February 2010. The main outcomes included survival to hospital discharge, incidence of IHCA, and prognostic factors related to hospital mortality. We also investigated preventable cases. RESULTS: We identified 238 index cases of IHCA. The average incidence of IHCA was 0.145 IHCAs per 1,000 patient admissions. Survival to hospital discharge was $19 \%$ (46 cases), $66 \%$ of which were due to non-cardiac causes, and $77 \%$ were due to medical illnesses. The most common first documented rhythm was pulseless electrical activity (38\%). Two hundred three cases $(85.3 \%)$ of IHCA were witnessed at the event; 135 cases $(56.7 \%)$ were monitored at the event. Non-witnessed cases, monitored cases, night onset, medical illness, metastatic cancer, intubation, and long duration of cardiopulmonary resuscitation were significantly associated with hospital mortality. We identified 91 preventable cases $(38 \%)$. Respiratory insufficiency (37 cases, $41 \%$ ) was one of major cause of preventable IHCA. CONCLUSIONS: Witnessed IHCAs in the general ward had a higher rate of survival to hospital discharge; however, monitored cases had a lower rate of survival to hospital discharge. Respiratory insufficiency was a major preventable cause of IHCA. In consideration of the preventable IHCAs, further studies should be performed on monitoring practices in general wards. Key words: in-hospital cardiac arrest; general ward; hospital mortality; monitoring; witnessed. [Respir Care 2013;58(11):1937-1944. (C) 2013 Daedalus Enterprises]
\end{abstract}

\section{Introduction}

The majority of cases of in-hospital cardiac arrest (IHCA) are cardiac in origin, similar to out-of-hospital cardiac

Dr Chon is affiliated with the Department of Pulmonary and Critical Care Medicine, Chungju Hospital, School of Medicine, Konkuk University, Chungju, Chungcheongbuk-do, Korea. Mrs Lee and Mrs Shin are affiliated with the Medical Emergency Team; and Drs Huh, Lim, Koh, and Hong are affiliated with the Department of Pulmonary and Critical Care Medicine, Asan Medical Center, College of Medicine, University of Ulsan, Seoul, Korea.

The authors have disclosed no conflicts of interest.

Supplementary material related to this paper is available at http:// www.rcjournal.com. arrest. ${ }^{1,2}$ Many studies have reported survival to discharge rates of $15-20 \%$ for IHCA, which are much lower than the rates for out-of-hospital cardiac arrest. ${ }^{1,3-7}$ A few studies report higher survival-to-discharge rates, of up to $45 \%$ by the Medical Emergency Team activities. ${ }^{8-10}$ In addition, the incidence of IHCA has been reported as 1-4 arrests per 1,000 patient admissions. ${ }^{4,11,12}$ However, there are few studies on the epidemiology and clinical outcomes of IHCA

\footnotetext{
Correspondence: Sang-Bum Hong MD PhD, Department of Pulmonary and Critical Care Medicine, Asan Medical Center, College of Medicine, University of Ulsan, 88 Olympicro, 43 Gil, Songpa-gu, Seoul, Korea. E-mail: sbhong@amc.seoul.kr.
}

DOI: $10.4187 /$ respcare. 02448 
cases in general wards. Also, the response to IHCA in general wards is expected to be less efficient than in the ICU because of delayed diagnosis, poor monitoring, and the lack of equipment and well trained staff.,312-14

A paper by Brady et al reported that patients who have witnessed and/or monitored cardiac arrest have a significantly higher rate of survival to hospital discharge than patients whose cardiac arrest is neither monitored nor witnessed. ${ }^{15}$ We hypothesized that survival to hospital discharge after IHCA would be significantly different for patients in general wards than those in ICUs. Hence, we investigated the clinical outcomes of IHCA cases that occurred in the general ward of a university hospital and that were witnessed and/or monitored. In addition, we further investigated IHCAs that could have been prevented in this setting. We believe this study provides valuable information regarding monitoring strategies to reduce the occurrence of IHCA in the general ward.

\section{Methods}

This study was approved by the ethics committee of Asan Medical Center, which waived the requirement for informed consent. In March 2008 we structured the Medical Emergency Team system at Asan Medical Center to include crisis conditions and IHCA cases in the general ward. All Medical Emergency Team members screened for abnormal signs in all in-patients, according to the Medical Emergency Team screening criteria. The screening criteria for Medical Emergency Team activation (see the supplementary materials at http://www.rcjournal.com) were modified from the Medical Emergency Response Improvement Team study criteria. ${ }^{16}$ We prospectively gathered data on all IHCA events that occurred in the general ward of Asan Medical Center between March 2008 and February 2010 and that were recorded by the Medical Emergency Team activity records. IHCA events were recorded in the electronic medical records according to the Utstein template reporting guidelines for IHCA. ${ }^{17}$ Also, IHCA events were described in detail according to the 2007 operating definitions by the American Heart Association (American Heart Association. Operational Definitions: CPA Event. NRCPR v.6.00; 2007). All data were documented by the Medical Emergency Team regular nurses.

\section{Hospital}

Asan Medical Center is affiliated with the University of Ulsan, the tertiary referral hospital of Seoul, South Korea; its in-patient sites admit a wide range of adult medical and surgical patients. In 2008, a total of 2,406 beds were available for approximately 774,000 admissions and 2,200 inpatients per day, and 5,600 highly difficult surgical pro-

\section{QUICK LOOK}

\section{Current knowledge}

The majority of in-hospital cardiac arrests (IHCAs) are cardiac in origin. Survival to discharge after IHCA is frequently worse than after out-of-hospital cardiac arrest. IHCA outside of the ICU, in a general ward, has been associated with poor outcome, because diagnosis, monitoring, equipment, and staff training may be suboptimal in a general ward.

\section{What this paper contributes to our knowledge}

Witnessed IHCAs in a general ward had significantly better survival to discharge than monitored IHCAs. The most common preventable cause of IHCA was respiratory insufficiency.

cedures were performed. In 2009, approximately 2,740 beds were available for approximately 871,000 admissions per year and 2,400 in-patients per day, and 5,700 highly difficult surgical procedures were performed.

\section{Data Collection}

All patients $\geq 18$ years old who experienced a cardiac arrest in the general ward and required cardiopulmonary resuscitation (CPR) or defibrillation were included in this analysis. Only index cases were included. An index case was defined as the first cardiac arrest of a patient who experienced more than one cardiac arrest during the same hospitalization. We excluded all cardiac arrests for which resuscitation was initiated outside of the hospital, prior to arrival at the emergency department, and events that involved defibrillation, ventricular fibrillation, or pulseless ventricular tachycardia, and were treated using only an implantable cardioverter-defibrillator. We also excluded all cardiac arrests that occurred in any critical care area (eg, ICU, operating room, emergency department).

We reviewed the electronic medical records of the 238 identified cases and extracted relevant information regarding IHCAs (ie, immediate causes associated with the event, and preventable cases). In our study a preventable case was defined as a missed predictable events plus potentially avoidable events. Missed predictable events were defined as a missed objective or clear evidence of patient deterioration within the 8 hours before cardiac arrest. Potentially avoidable events included: failure to adhere to established hospital patient care policy; delay dealing with patient needs, including $\geq 20$ min delay in activating the Medical Emergency Team; inadequate monitoring or surveillance; procedural or surgical complications that were coincident with IHCA; and do-not-resuscitate orders issues. ${ }^{18}$ 
Table 1. Baseline Characteristics of Subjects With Witnessed and Non-Witnessed In-Hospital Cardiac Arrest

\begin{tabular}{|c|c|c|c|c|}
\hline & $\begin{array}{l}\text { Witnessed } \\
n=203\end{array}$ & $\begin{array}{c}\text { Non-witnessed } \\
n=35\end{array}$ & $\begin{array}{c}\text { Total } \\
n=238\end{array}$ & $P$ \\
\hline Age, mean $\pm \mathrm{SD}$ y & $61.9 \pm 15.1$ & $57.4 \pm 15.7$ & $61.3 \pm 15.2$ & .12 \\
\hline Sex, male & $120(59.1)$ & $22(62.9)$ & $142(59.7)$ & .68 \\
\hline Onset of event, daytime (7:00 AM to 11:00 PM) & $153(75.4)$ & 17 (48.6) & $170(71.4)$ & .001 \\
\hline \multicolumn{5}{|l|}{ Illness category } \\
\hline Medical illness & $156(76.8)$ & $27(77.1)$ & $183(76.9)$ & .97 \\
\hline \multicolumn{5}{|l|}{ Preexisting conditions } \\
\hline Malignancy & $101(49.8)$ & $16(45.7)$ & $117(49.2)$ & .66 \\
\hline Metastasis & $48(23.6)$ & $9(25.7)$ & $57(23.9)$ & .79 \\
\hline Acute coronary syndrome prior & $26(12.8)$ & $8(22.9)$ & $34(14.3)$ & .12 \\
\hline Acute coronary syndrome present & $9(4.4)$ & $3(8.6)$ & $12(5)$ & .39 \\
\hline Arrhythmia & $29(14.3)$ & $5(14.3)$ & $34(14.3)$ & $>.99$ \\
\hline Non-stroke & $30(14.8)$ & $1(2.9)$ & $31(13)$ & .058 \\
\hline Stroke & $7(3.4)$ & $1(2.9)$ & $8(3.4)$ & $>.99$ \\
\hline Congestive heart failure prior & $18(8.9)$ & $5(14.3)$ & $23(9.7)$ & .35 \\
\hline Congestive heart failure present & $18(8.9)$ & $4(11.4)$ & $22(9.2)$ & .54 \\
\hline Hypotension & $45(22.2)$ & $3(8.6)$ & $48(20.2)$ & .06 \\
\hline Vasopressor & $29(14.3)$ & $3(8.6)$ & $32(13.4)$ & .59 \\
\hline Hypertension & $80(39.4)$ & $18(51.4)$ & $98(41.2)$ & .18 \\
\hline Diabetes mellitus & $63(31)$ & $14(40)$ & $77(32.4)$ & .30 \\
\hline Hepatic insufficiency & $37(18.2)$ & $2(5.7)$ & $39(16.4)$ & .07 \\
\hline Pneumonia & $22(10.8)$ & $4(11.4)$ & $26(10.9)$ & $>.99$ \\
\hline Respiratory insufficiency & $56(27.6)$ & $2(5.7)$ & $58(24.4)$ & .005 \\
\hline Septicemia & $17(8.4)$ & $2(5.7)$ & $19(8)$ & $>.99$ \\
\hline Renal insufficiency & $60(29.6)$ & $7(20)$ & $67(28.2)$ & .25 \\
\hline Metabolic abnormality & $31(15.3)$ & $2(5.7)$ & $33(13.9)$ & .19 \\
\hline Human immunodeficiency virus infection & $0(0)$ & $1(2.9)$ & $1(0.4)$ & .15 \\
\hline \multicolumn{5}{|l|}{ Interventions in place before the event } \\
\hline Vascular access & $183(90.1)$ & $33(94.3)$ & $216(90.8)$ & .75 \\
\hline Oxygen supplementation & $130(64)$ & $16(45.7)$ & $146(61.3)$ & .04 \\
\hline Electrocardiography monitoring & $121(59.9)$ & $5(14.3)$ & $126(53.2)$ & $<.001$ \\
\hline Pulse oximetry & $2(1)$ & $0(0)$ & $2(0.8)$ & $>.99$ \\
\hline Intravenous vasoactive agent & $33(16.3)$ & $6(17.1)$ & $39(16.4)$ & .90 \\
\hline Invasive airway* & $36(17.7)$ & $1(2.9)$ & $37(15.5)$ & .03 \\
\hline Intravenous opioid agents & $33(16.3)$ & $3(8.6)$ & $36(15.1)$ & .24 \\
\hline Mechanical ventilation & $15(7.4)$ & $0(0)$ & $15(6.3)$ & .14 \\
\hline Arterial catheter & $9(4.4)$ & $0(0)$ & $9(3.8)$ & .36 \\
\hline Chest tube & $5(2.5)$ & $0(0)$ & $5(2.1)$ & $>.99$ \\
\hline Intravenous anti-arrhythmic agent & $4(2)$ & $0(0)$ & $4(1.7)$ & $>.99$ \\
\hline Patient-controlled analgesia & $1(0.5)$ & $2(5.7)$ & $3(1.3)$ & .057 \\
\hline Pacemaker, internal & $2(1)$ & $0(0)$ & $2(0.8)$ & $>.99$ \\
\hline Implantable cardioverter-defibrillator & $2(1)$ & $0(0)$ & $2(0.8)$ & $>.99$ \\
\hline
\end{tabular}

\section{Statistical Analysis}

Data are expressed as mean $\pm \mathrm{SD}$, or median and IQR if non-normally distributed. Nominal variables were compared using the chi-square test or Fisher exact test, and the mean values of the 2 groups were compared using the Student $t$ test. Non-normally distributed continuous vari- ables were compared using the Mann-Whitney U test. We used multivariate logistic regression modeling to determine the prognostic factors that were associated with hospital mortality after adjusting for confounders. Backward elimination was performed using the likelihood ratio method. Model adequacy was assessed using the HosmerLemeshow goodness-of-fit test. Some data are presented 


\section{Clinical Outcomes of Witnessed and Monitored Cases of In-Hospital Cardiac Arrest}

Table 2. Characteristics of the Witnessed and Non-Witnessed In-Hospital Cardiac Arrest

\begin{tabular}{|c|c|c|c|c|}
\hline & $\begin{array}{l}\text { Witnessed } \\
n=203\end{array}$ & $\begin{array}{l}\text { Non-witnessed } \\
\quad n=35\end{array}$ & $\begin{array}{c}\text { Total } \\
n=238\end{array}$ & $P$ \\
\hline First documented rhythm & & & & .001 \\
\hline Pulseless ventricular tachycardia/ventricular fibrillation & $31(15.3)$ & $3(8.6)$ & $34(14.3)$ & \\
\hline Pulseless electrical activity & $85(41.9)$ & $6(17.1)$ & $91(38.2)$ & \\
\hline Asystole & $35(17.2)$ & $15(42.9)$ & $50(21)$ & \\
\hline Unknown & $52(25.6)$ & $11(31.4)$ & $63(26.5)$ & \\
\hline Discovery status of event & & & & $<.001$ \\
\hline Monitored & $128(63.1)$ & $7(20)$ & $135(56.7)$ & \\
\hline Electrocardiography monitoring only & 8 & 3 & 11 & \\
\hline Pulse oximetery only & 32 & 3 & 35 & \\
\hline Both monitoring & 88 & 1 & 89 & \\
\hline Immediate cause of the event & & & & .93 \\
\hline Cardiac & $68(33.5)$ & $12(34.3)$ & $80(33.6)$ & \\
\hline Pulseless ventricular tachycardia/ventricular fibrillation & $27(13.3)$ & $2(5.7)$ & $29(12.2)$ & \\
\hline Acute coronary syndrome & $10(4.9)$ & $4(11.4)$ & $14(5.9)$ & \\
\hline Acute pulmonary edema & $10(4.9)$ & $4(11.4)$ & $14(5.9)$ & \\
\hline Acute pulmonary embolism & $8(3.9)$ & $1(2.9)$ & $9(3.8)$ & \\
\hline Other* & $12(5.9)$ & $0(0)$ & $12(5)$ & \\
\hline Unknown & $1(0.5)$ & $1(2.9)$ & $2(0.8)$ & \\
\hline Non-cardiac & $135(66.5)$ & $23(65.7)$ & $158(66.4)$ & \\
\hline Cerebrovascular & $4(2)$ & $2(5.7)$ & $6(2.5)$ & \\
\hline Asphyxia/Airway problem & $29(14.3)$ & $8(22.9)$ & $37(15.5)$ & \\
\hline Hypovolemic shock & $32(15.8)$ & $3(8.6)$ & $35(14.7)$ & \\
\hline Septic shock & $25(12.3)$ & $2(5.7)$ & $27(11.3)$ & \\
\hline Acute respiratory insufficiency & $34(16.7)$ & $7(20)$ & $41(17.2)$ & \\
\hline Anaphylaxis & $9(4.4)$ & $0(0)$ & $9(3.8)$ & \\
\hline Other $\dagger$ & $2(1)$ & $1(2.9)$ & $3(1.3)$ & \\
\hline Arrived time of Medical Emergency Team, min & $1(0.5-2)$ & $1(0.5-2)$ & $1(0.5-2)$ & .49 \\
\hline Duration of CPR, min & $12(5-30)$ & $20(10-38)$ & $14(5-32)$ & .10 \\
\hline Duration of CPR, min & & & & .20 \\
\hline $0-15$ & $112(55.2)$ & $14(40)$ & $126(52.9)$ & \\
\hline $15-35$ & $50(24.6)$ & $10(28.6)$ & $60(25.2)$ & \\
\hline$>35$ & $41(20.2)$ & $11(31.4)$ & $52(21.8)$ & \\
\hline Return of spontaneous circulation, min & $11(5-20)$ & $16(6.25-27.5)$ & $12(5-21)$ & .19 \\
\hline \multicolumn{5}{|c|}{$\begin{array}{l}\text { Values are number (\%). } \\
\text { * Other cardiac causes: aortic dissection in 3, ruptured aneurysm in 2, air embolism in 2, other type of arrhythmia in 2, causes related to the procedure in } 1 \text {, progression to aortic stenosis in } 1 . \\
\text { † Other non-cardiac causes: metabolic acidosis in 2, hypoglycemia in } 1 .\end{array}$} \\
\hline
\end{tabular}

as odds ratios with $95 \%$ CIs. Significance was defined as a 2 -sided $P<.05$. Statistics software (SPSS 17.0, SPSS, Chicago, Illinois) was used to perform all statistical analyses.

\section{Results}

We identified 238 index cases of IHCA between March 2008 and February 2010. The average estimated incidence of IHCA was 0.145 events per 1,000 patient admissions. Of the 238 IHCAs, $66 \%$ were due to non-cardiac causes, and $77 \%$ were due to medical illnesses. The mean $\pm \mathrm{SD}$ age of the subjects was $61.3 \pm 15.2 \mathrm{y}$, and $60 \%$ were male. The most common underlying disease was malignancy
(114 cases, 48\%). Pulseless electrical activity was the most common first documented rhythm (38\%). Two hundred three IHCAs $(85.3 \%)$ were witnessed, and $128(63.1 \%)$ of those were monitored. All monitored cases at events were 135 cases $(56.7 \%)$. The median arrival of the Medical Emergency Team time was $1 \mathrm{~min}$ (IQR $0.5-2 \mathrm{~min}$ ). The median duration of CPR was 14 min (IQR 5-32 min). One hundred fifty-one cases $(63 \%)$ achieved return of spontaneous circulation. The median time of return of spontaneous circulation was $12 \mathrm{~min}$ (IQR 5-21 min). Survival to hospital discharge was 19\% (46 cases). Do-not-resuscitate status prior to the event was identified in 11 cases $(4.6 \%)$.

Witnessed IHCAs occurred more frequently during the daytime (153 cases, 75.4\%) than non-witnessed IHCAs. 


\section{Clinical Outcomes of Witnessed and Monitored Cases of In-Hospital Cardiac Arrest}

Table 3. Clinical Outcomes of Subjects With Witnessed and NonWitnessed In-Hospital Cardiac Arrest

\begin{tabular}{lcccc}
\hline \hline & $\begin{array}{c}\text { Witnessed } \\
n=203\end{array}$ & $\begin{array}{c}\text { Non-witnessed } \\
n=35\end{array}$ & $\begin{array}{c}\text { Total } \\
n=238\end{array}$ & $P$ \\
\hline $\begin{array}{c}\text { Return of spontaneous } \\
\text { circulation achieved }\end{array}$ & $134(66)$ & $17(48.6)$ & $151(63.4)$ & .048 \\
$\begin{array}{c}\text { Survival to hospital } \\
\text { discharge }\end{array}$ & $44(21.7)$ & $2(5.7)$ & $46(19.3)$ & .03 \\
\hline Values are number (\%). & & & & \\
\hline
\end{tabular}

Table 4. Prognostic Factors Associated With the Return of Spontaneous Circulation: Multivariate Logistic Regression Model*

\begin{tabular}{lcr}
\hline \hline & $\begin{array}{c}\text { Odds Ratio } \\
(95 \% \text { CI })\end{array}$ & $P$ \\
\hline Medical illness & $0.333(0.118-0.934)$ & .04 \\
Preexisting metastatic cancer & $0.189(0.073-0.492)$ & .001 \\
$\begin{array}{l}\text { Initial recorded rhythm non-ventricular } \\
\text { tachycardia/ventricular fibrillation }\end{array}$ & $0.219(0.049-0.979)$ & .047 \\
Intubation & $3.888(1.507-10.032)$ & .005 \\
$\begin{array}{l}\text { Duration of cardiopulmonary } \\
\quad \text { resuscitation, min }\end{array}$ & & $<.001$ \\
$0-15$ & 1.0 & \\
15-35 & $0.194(0.076-0.495)$ & \\
$>35$ & $0.009(0.002-0.036)$ &
\end{tabular}

* Variables included in the logistic regression model: time of onset, age, illness (medical/surgical), chronic liver disease as the underlying disease, preexisting malignancy, preexisting metastatic cancer, witnessed case, monitored case, initial recorded rhythm (ventricular tachycardia/ventricular fibrillation vs non-ventricular tachycardia/ventricular fibrillation), defibrillation, intubation, vascular access, immediate cause (cardiac/non-cardiac), atropine use, and duration of cardiopulmonary resuscitation.

Taking into account preexisting conditions, the witnessed cases were more significantly associated with respiratory insufficiency (56 cases, 27.6\%) than the non-witnessed cases ( 2 cases, 5.6\%). Before the IHCA event the witnessed cases had significantly more frequent oxygen supplementation (130 cases, 64\%), electrocardiographic monitoring (121 cases, 59.9\%), and invasive airway interventions (36 cases, 17.7\%) than the non-witnessed cases (oxygen supplementation 16 cases, $45.7 \%$, electrocardiogram monitoring 5 cases, $14.3 \%$, and invasive airway interventions 1 case, $2.9 \%$ ).

The baseline characteristics of the IHCA incidents are shown in Table 1. The witnessed cases had pulseless electrical activity as the first documented rhythm, and the non-witnessed group had asystole as the first documented rhythm. The witnessed group had significantly more monitored cases (128 cases, 63.1\%) than the non-witnessed group ( 7 cases, $20 \%$ ).

The IHCA characteristics are detailed in Table 2 which also shows the immediate causes of the IHCAs, of which $158(66 \%)$ were non-cardiac causes. The most common
Table 5. Prognostic Factors Associated With Hospital Mortality: Multivariate Logistic Regression Model*

\begin{tabular}{|c|c|c|}
\hline & $\begin{array}{l}\text { Odds Ratio } \\
(95 \% \mathrm{CI})\end{array}$ & $P$ \\
\hline Nighttime onset (7:00 AM to 11:00 PM) & $6.311(1.449-27.473)$ & .01 \\
\hline Medical illness & $4.712(1.753-12.668)$ & .002 \\
\hline Preexisting metastatic cancer & $7.424(1.221-45.159)$ & .003 \\
\hline Witnessed case & $0.138(0.021-0.909)$ & .04 \\
\hline Monitored case & $3.604(1.301-9.988)$ & .01 \\
\hline Intubation & $2.769(1.061-7.223)$ & .04 \\
\hline \multicolumn{2}{|l|}{$\begin{array}{l}\text { Duration of cardiopulmonary } \\
\text { resuscitation, min }\end{array}$} & .007 \\
\hline $0-15$ & 1.0 & \\
\hline $15-35$ & $2.579(0.765-8.698)$ & \\
\hline$>35$ & $13.01(1.703-99.366)$ & \\
\hline \multicolumn{3}{|c|}{$\begin{array}{l}\text { * Variables included in the logistic regression model: time of onset, age, illness } \\
\text { (medical/surgical), malignancy as underlying disease, chronic liver disease as underlying } \\
\text { disease, chronic kidney disease as underlying disease, preexisting malignancy, preexisting } \\
\text { metastatic cancer, witnessed case, monitored case, initial recorded rhythm (ventricular } \\
\text { tachycardia/ventricular fibrillation vs non-ventricular tachycardia/ventricular fibrillation), } \\
\text { defibrillation, intubation, vascular access, vasoactive infusion, time until arrival of Medical } \\
\text { Emergency Team, immediate cause (cardiac/non-cardiac), preventable case, and duration of } \\
\text { cardiopulmonary resuscitation. }\end{array}$} \\
\hline
\end{tabular}

non-cardiac cause was acute respiratory insufficiency (40 cases, 16.7\%). The most common cardiac cause was pulseless ventricular tachycardia/fibrillation (29 cases, $12.2 \%)$. The witnessed group had significantly more subjects who achieved return of spontaneous circulation (134 cases, 66\%) and a significantly higher rate of survival to hospital discharge (44 cases, 21.7\%) than the nonwitnessed group (achieved return of spontaneous circulation 17 cases, $48.6 \%$, survival to hospital discharge 2 cases, $5.7 \%)$.

The clinical outcomes are detailed in Table 3. The monitored cases did not have better survival to hospital discharge. These cases are detailed in the supplementary materials at http://www.rcjournal.com.

Using multivariate logistic regression we identified 5 significant independent variables associated with return of spontaneous circulation: surgical illness, non-metastatic cancer as a preexisting condition, ventricular tachycardia/ fibrillation as the initially recorded rhythm, intubation, and short duration of CPR (Table 4). We also identified 7 significant independent factors associated with hospital mortality: night onset, medical illness, metastatic cancer as a preexisting condition, non-witnessed case, monitored case, intubation, and long duration of CPR (Table 5).

We identified 91 (38\%) preventable cases, of which 24 (26\%) were missed predictable events and 67 (74\%) were potentially avoidable events. The preventable IHCAs are detailed in Table 6. Respiratory insufficiency (37 cases, $41 \%$ ), metastatic cancer (33 cases, 36\%), metabolic/electrolyte abnormalities (24 cases, $26 \%$ ), and acute mental changes $(19,21 \%)$ represent the majority of the prevent- 


\section{Clinical Outcomes of Witnessed and Monitored Cases of In-Hospital Cardiac Arrest}

Table 6. Characteristics of the Preventable Cases of In-Hospital Cardiac Arrest in the Present Study $(n=91)$

\begin{tabular}{lc}
\hline \hline & No. $(\%)$ \\
\hline Missed predictable event & $24(26)$ \\
Potentially avoidable event & $67(74)$ \\
$\quad$ Failure to adhere to established hospital & $5(5)$ \\
$\quad$ patient care policy & \\
Delay dealing with patient needs & $6(7)$ \\
Inadequate monitoring/surveillance & $9(10)$ \\
Procedure/surgical complication & $2(2)$ \\
Do-not-resuscitate order & $45(50)$ \\
\hline
\end{tabular}

able cases. In contrast, congestive heart failure (1 case, $1 \%$ ) and arrhythmia (7 cases, $8 \%$ ) represent the minority of the preventable cases. Preventable IHCAs according to preexisting conditions are detailed in the supplementary materials at http://www.rcjournal.com.

\section{Discussion}

Although the monitored cases identified in this study did not have better survival to hospital discharge, compared with the results from Brady et $a l,{ }^{15}$ the patients with witnessed events had a higher rate of return of spontaneous circulation and a higher rate of survival to hospital discharge. Also, witnessed event was a significant prognostic factor associated with hospital mortality, according to the multivariate logistic regression model. In this study, non-cardiac causes resulted in the majority of the IHCA cases in the general ward of our hospital. Also, the majority of the preventable cases were the result of respiratory insufficiency or metastatic cancer. Considering all of these results, additional monitoring for respiratory insufficiency could reduce the occurrence of IHCA in the general ward, so further studies are needed on that issue.

Our data demonstrate a high proportion (85.3\%) of witnessed cases, in comparison with previous studies (61$77 \%, 48.6 \%$ ), excluding IHCAs that occurred in critical care areas. ${ }^{19,20}$ Witnessed IHCAs typically have a good prognosis in terms of mortality. ${ }^{15,21}$ Although previous studies of data from the National Registry of CPR included IHCAs in the ICU, those results are consistent with the results of our study under the relatively higher proportion of witnessed cases. ${ }^{15,21}$ There is also indirect evidence that the higher proportion of witnessed cases in the general ward may be due to the Medical Emergency Team's screening system through the electronic medical records in our hospital.

Recently, Brady et al reported that patients with monitored and/or witnessed cardiac arrest have a significantly higher rate of survival to discharge than patients whose cardiac arrests are neither monitored nor witnessed, ${ }^{15}$ and that cardiac monitoring conferred no additional benefits over the direct observation of patients suffering IHCA. In contrast, our results indicate that monitored patients, paradoxically, had worse hospital mortality. In our study, the monitored cases presented with significantly more noncardiac preexisting conditions (eg, respiratory insufficiency, hypotension, hepatic insufficiency, metabolic abnormality) and interventions before the event (eg, vascular access, oxygen supplementation, invasive airway management, the administration of intravenous opioids, mechanical ventilation) than the non-monitored subjects. This finding suggests that the monitored subjects might have had more severe illness than the non-monitored subjects, but we did not measure illness severity.

Evidence of deterioration within the 8 hours prior to arrest has been reported in up to $84 \%$ of cases. The most common findings include respiratory problems, deterioration of mental status, and hemodynamic instability. ${ }^{22-25}$ In our study, the preexisting conditions of IHCA were found to be similar to the above cited studies, except for metastatic cancer. Neither a previously reported study nor this study has reported any benefit of cardiac monitoring on mortality. ${ }^{15}$ We believe that the early application of monitoring systems, especially those that identify respiratory insufficiency in high-risk patients in the general ward, may reduce the incidence of cardiac arrest in the general ward.

In cases of metastatic cancer, most of the subjects had do-not-resuscitate orders and important preventable cases. This explains why metastatic cancer is one of the most common causes of preventable events. Until recently, in South Korea there were few guidelines on advanced medical directives, including do-not-resuscitate directives. Formal guidelines should be drafted in consensus meetings.

We find that survival to hospital discharge rate can demonstrate large variations, depending on the center and the inclusion of critical care areas. ${ }^{1,3-7,19,20,26}$ Based on our findings, the majority of cases of IHCA that occur in the general ward are non-cardiac. There are several possible explanations for differences in survival to hospital discharge after IHCA in the general ward. First, these differences may be due to racial or national characteristics. Merchant et al reported that hospitals with higher proportions of black patients had higher rates of case-mix adjusted IHCA, ${ }^{27}$ and Chan et al reported that black patients who present with IHCA are significantly less likely to survive to discharge than white patients. ${ }^{28}$ Second, it may be partly due to the quality of care provided by the hospital. Skrifvars et al reported that a locally implemented, strong, inhospital chain of survival is probably the only way to improve clinical outcomes following IHCA. ${ }^{29}$ Medical Emergency Team implementation may have allowed better survival to hospital discharge rate in our hospital. In addition, the differences in the survival to hospital discharge rate between this study and the study by Chakra- 


\section{Clinical Outcomes of Witnessed and Monitored Cases of In-Hospital Cardiac Arrest}

varthy et $\mathrm{al}^{26}$ could be attributed to the higher proportion of non-cardiac causes and non-cardiac preexisting conditions in our data. Third, Neiman et al indicated that donot-resuscitate decisions affect the survival rate: when they excluded do-not-resuscitate patients, they found a $15 \%$ increase in survival to hospital discharge. ${ }^{30}$ Despite the very low proportion of do-not-resuscitate patients in our study, we found a relatively good survival to hospital discharge, perhaps because of the Medical Emergency Team.

Pulseless electrical activity was the most common first documented rhythm in this study, followed by unknown, asystole, and ventricular tachycardia/fibrillation. This low proportion of ventricular tachycardia/fibrillation is similar to studies performed in critical care areas. ${ }^{19,26}$ Hypoxia and hypotension as the precipitating causes of IHCA are more likely to induce pulseless electrical activity or asystole than ventricular tachycardia/fibrillation. ${ }^{1,22}$ A high proportion of non-cardiac cases in the present study supports the results of previous studies. Another possible explanation for the low proportion of ventricular tachycardia/fibrillation is that there was less monitoring in our study, relative to the National Registry of CPR study, because we included only the general ward and excluded critical care areas. ${ }^{1}$

There are notable limitations to our study. First, we did not measure CPR quality according to advanced cardiac life support guidelines provided by the American Heart Association. ${ }^{31}$ However, according to the high rate of return of spontaneous circulation and survival, and the relatively short amount of time spent performing CPR, we believe that the quality of CPR in our study was quite good. Second, we did not measure the Cerebral Performance Category score ${ }^{32}$ and therefore could not assess functional outcomes following IHCA.

\section{Conclusions}

Witnessed IHCAs in the general ward had a significantly higher rate of survival to hospital discharge, whereas monitored IHCAs had lower survival to hospital discharge. Non-cardiac causes resulted in the majority of the IHCAs in the general ward. The most common preventable cause of IHCA was respiratory insufficiency. Monitoring for respiratory insufficiency might reduce the occurrence of IHCA in the general ward, but further study is needed. In addition, the role of advanced medical directives in hospital policy, including do-not-resuscitate directives, should be further discussed and clarified.

\section{ACKNOWLEDGMENTS}

We thank the members of the Medical Emergency Team at Asan Medical Center.

\section{REFERENCES}

1. Peberdy MA, Kaye W, Ornato JP, Larkin GL, Nadkarni V, Mancini ME, et al. Cardiopulmonary resuscitation of adults in the hospital: a report of 14720 cardiac arrests from the National Registry of Cardiopulmonary Resuscitation. Resuscitation 2003;58(3):297-308.

2. Yokoyama H, Yonemoto N, Yonezawa K, Fuse J, Shimizu N, Hayashi $\mathrm{T}$, et al; J-RCPR Investigators. Report from the Japanese registry of CPR for in-hospital cardiac arrest (J-RCPR). Circ J 2011;75(4):815822 .

3. Tunstall-Pedoe H, Bailey L, Chamberlain DA, Marsden AK, Ward ME, Zideman DA. Survey of 3765 cardiopulmonary resuscitations in British hospitals (the BRESUS study): methods and overall results. BMJ 1992;304(6838):1347-1351.

4. Hodgetts TJ, Kenward G, Vlackonikolis I, Payne S, Castle N, Crouch $\mathrm{R}$, et al. Incidence, location and reasons for avoidable in-hospital cardiac arrest in a district general hospital. Resuscitation 2002;54(2): 115-123.

5. Nadkarni VM, Larkin GL, Peberdy MA, Carey SM, Kaye W, Mancini ME, et al National Registry of Cardiopulmonary Resuscitation Investigators. First documented rhythm and clinical outcome from in-hospital cardiac arrest among children and adults. JAMA 2006; 295(1):50-57.

6. Gwinnutt CL, Columb M, Harris R. Outcome after cardiac arrest in adults in UK hospitals: effect of the 1997 guidelines. Resuscitation 2000;47(2):125-135.

7. Cooper S, Cade J. Predicting survival, in-hospital cardiac arrests: resuscitation survival variables and training effectiveness. Resuscitation 1997;35(1):17-22.

8. Herlitz J, Andreasson AC, Bang A, Aune S, Lindqvist J. Long-term prognosis among survivors after in-hospital cardiac arrest. Resuscitation 2000;45(3):167-171.

9. Fredriksson M, Aune S, Thoren AB, Herlitz J. In-hospital cardiac arrest-an Utstein style report of seven years experience from the Sahlgrenska University Hospital. Resuscitation 2006;68(3):351-358.

10. Buist MD, Moore GE, Bernard SA, Waxman BP, Anderson JN, Nguyen TV. Effects of a medical emergency team on reduction of incidence of and mortality from unexpected cardiac arrests in hospital: preliminary study. BMJ 2002;324(7334):387-390.

11. Skogvoll E, Isern E, Sangolt GK, Gisvold SE. In-hospital cardiopulmonary resuscitation. 5 years' incidence and survival according to the Utstein template. Acta Anaesthesiol Scand 1999;43(2):177-184.

12. Sandroni C, Ferro G, Santangelo S, Tortora F, Mistura L, Cavallaro F, et al. In-hospital cardiac arrest: survival depends mainly on the effectiveness of the emergency response. Resuscitation 2004;62(3): 291-297.

13. Dumot JA, Burval DJ, Sprung J, Waters JH, Mraovic B, Karafa MT, et al. Outcome of adult cardiopulmonary resuscitations at a tertiary referral center including results of "limited" resuscitations. Arch Intern Med 2001;161(14):1751-1758.

14. Herlitz J, Bang A, Aune S, Ekstrom L, Lundstrom G, Holmberg S. Characteristics and outcome among patients suffering in-hospital cardiac arrest in monitored and non-monitored areas. Resuscitation 2001;48(2):125-135.

15. Brady WJ, Gurka KK, Mehring B, Peberdy MA, O'Connor RE; American Heart Association's Get with the Guidelines (formerly, NRCPR) Investigators. In-hospital cardiac arrest: Impact of monitoring and witnessed event on patient survival and neurologic status at hospital discharge. Resuscitation 2011;82(7):845-852.

16. Hillman K, Chen J, Cretikos M, Bellomo R, Brown D, Doig G, et al; MERIT Study Investigators. Introduction of the medical emergency team (MET) system: a cluster-randomised controlled trial. Lancet 2005;365(9477):2091-2097.

17. Jacobs I, Nadkarni V, Bahr J, Berg RA, Billi JE, Bossaert L, et al; International Liaison Committee on Resuscitation. Cardiac arrest 


\section{Clinical Outcomes of Witnessed and Monitored Cases of In-Hospital Cardiac Arrest}

and cardiopulmonary resuscitation outcome reports: update and simplification of the Utstein templates for resuscitation registries. A statement for healthcare professionals from a task force of the international liaison committee on resuscitation (American Heart Association, European Resuscitation Council, Australian Resuscitation Council, New Zealand Resuscitation Council, Heart and Stroke Foundation of Canada, InterAmerican Heart Foundation, Resuscitation Council of Southern Africa). Resuscitation 2004;63(3):233-249.

18. Galhotra S, DeVita MA, Simmons RL, Dew MA; Members of the Medical Emergency Response Improvement Team (MERIT) Committee. Mature rapid response system and potentially avoidable cardiopulmonary arrests in hospital. Qual Saf Health Care 2007;16(4): 260-265.

19. Skrifvars MB, Saarinen K, Ikola K, Kuisma M. Improved survival after in-hospital cardiac arrest outside critical care areas. Acta Anaesthesiol Scand 2005;49(10):1534-1539.

20. Cohn AC, Wilson WM, Yan B, Joshi SB, Heily M, Morley P, et al. Analysis of clinical outcomes following in-hospital adult cardiac arrest. Intern Med J 2004;34(7):398-402.

21. Larkin GL, Copes WS, Nathanson BH, Kaye W. Pre-resuscitation factors associated with mortality in 49,130 cases of in-hospital cardiac arrest: a report from the National Registry for Cardiopulmonary Resuscitation. Resuscitation 2010;81(3):302-311.

22. Kause J, Smith G, Prytherch D, Parr M, Flabouris A, Hillman K; Intensive Care Society (UK); Australian and New Zealand Intensive Care Society Clinical Trials Group. A comparison of antecedents to cardiac arrests, deaths and emergency intensive care admissions in Australia and New Zealand, and the United Kingdom: the ACADEMIA study. Resuscitation 2004;62(3):275-282.

23. Schein RM, Hazday N, Pena M, Ruben BH, Sprung CL. Clinical antecedents to in-hospital cardiopulmonary arrest. Chest 1990;98(6): 1388-1392.
24. Franklin C, Mathew J. Developing strategies to prevent in-hospital cardiac arrest: analyzing responses of physicians and nurses in the hours before the event. Crit Care Med 1994;22(2):244-247.

25. Smith A, Wood J. Can some in-hospital cardio-respiratory arrests be prevented? Resuscitation 1998;37(3):133-137.

26. Chakravarthy M, Mitra S, Nonis L. Outcomes of in-hospital, out of intensive care and operation theatre cardiac arrests in a tertiary referral hospital. Indian heart J 2012;64(1):7-11.

27. Merchant RM, Yang L, Becker LB, Berg RA, Nadkarni V, Nichol G, et al; American Heart Association Get With the Guideline Resuscitation Investigators. Variability in case-mix adjusted in-hospital cardiac arrest rates. Med Care 2012;50(2):124-130.

28. Chan PS, Nichol G, Krumholz HM, Spertus JA, Jones PG, Peterson ED, et al; American Heart Association National Registry of Cardiopulmonary Resuscitation (NRCPR) Investigators. Racial differences in survival after in-hospital cardiac arrest. JAMA 2009;302(11):11951201.

29. Skrifvars MB, Castren M, Aune S, Thoren AB, Nurmi J, Herlitz J. Variability in survival after in-hospital cardiac arrest depending on the hospital level of care. Resuscitation 2007;73(1):73-81.

30. Niemann JT, Stratton SJ. The Utstein template and the effect of in-hospital decisions: the impact of do-not-attempt resuscitation status on survival to discharge statistics. Resuscitation 2001;51(3):233237.

31. ECC Committee, Subcommittees and Task Forces of the American Heart Association. 2005 American Heart Association guidelines for cardiopulmonary resuscitation and emergency cardiovascular care. Circulation 2005;112(Suppl 24):IV1-203.

32. Brain Resuscitation Clinical Trial I Study Group. A randomized clinical study of cardiopulmonary-cerebral resuscitation: design, methods, and patient characteristics. Am J Emerg Med 1986;4(1): $72-86$ 